\title{
Dynamic efficiency of Cournot and Bertrand competition: input versus output spillovers
}

\author{
Jeroen Hinloopen · Jan Vandekerckhove
}

Received: 26 November 2008 / Accepted: 18 July 2009 / Published online: 1 September 2009

C) The Author(s) 2009. This article is published with open access at Springerlink.com

\begin{abstract}
We consider the efficiency of Cournot and Bertrand equilibria in a duopoly with substitutable goods where firms invest in process $R \& D$ that generates input spillovers. Under Cournot competition firms always invest more in R\&D than under Bertrand competition. More importantly, Cournot competition yields lower prices than Bertrand competition when the R\&D production process is efficient, when spillovers are substantial, and when goods are not too differentiated. The range of cases for which total surplus under Cournot competition exceeds that under Bertrand competition is even larger as competition over quantities always yields the largest producers' surplus.
\end{abstract}

Keywords Bertrand competition · Cournot competition · Process R\&D · Efficiency · Spillovers

\section{JEL Classification L13}

\section{Introduction}

It is well known that in a duopoly with an exogenous market structure price (Bertrand) competition yields lower prices than quantity (Cournot) competition (Singh and Vives 1984; Cheng 1985). With Bertrand competition residual demand is more

\footnotetext{
J. Hinloopen $(\varangle)$

Universiteit van Amsterdam, FEB/ASE, Roetersstraat 11,

1018 WB Amsterdam, The Netherlands

e-mail: J.Hinloopen@uva.nl

URL: http://www.fee.uva.nl/io/jhinloopen

J. Hinloopen $\cdot$ J. Vandekerckhove

Katholieke Universiteit Leuven, FEB/MSI, Naamsestraat 69, 3000 Leuven, Belgium

e-mail: Jan.Vandekerckhove@econ.kuleuven.be
} 
sensitive to changes in price thereby yielding lower equilibrium prices (Martin 2002). Zanchettin (2006) shows that this result extends to duopolies with exogenous cost differences while for symmetric cost structures the result also extends to an oligopoly (Vives 1985). Häckner (2000) reveals however that in an oligopoly of complementary goods with exogenous quality differences the low-quality firms may charge higher prices under Bertrand competition than under Cournot competition. The switch from Cournot competition to Bertrand competition induces the high-quality firms to charge a lower price. And the resulting upward pressure on the demand for the low-quality complement then allows for a price increase. Hence (Häckner 2000, p. 238), "it is not evident which type of competition is more efficient."

If market structure is endogenous the traditional welfare comparison of Cournot and Bertrand competition may indeed be reversed. Cellini et al. (2004) and Mukherjee (2005) show that under free entry the number of firms entering under Cournot competition exceeds that under Bertrand competition. The resulting increase in the number of product varieties can more than compensate for the higher price that always obtains under Cournot competition.

Alternatively, the production function is endogenous in the sense that competition in the product market is preceded by a stage where firms conduct research and development (R\&D). This research can be aimed at lowering production costs (Qiu 1997), or at increasing product quality (Symeonidis 2003). Again the welfare comparison may be reversed as under Cournot competition incentives to invest in R\&D are higher than under Bertrand competition. ${ }^{1}$ With process R\&D, post-innovation production costs under Cournot competition are then reduced more than under Bertrand competition. This enhances the difference in profits under Cournot and Bertrand competition. As a result, total surplus under Cournot competition can exceed total surplus under Bertrand competition, despite the fact that prices under Bertrand competition are always lower than under Cournot competition (Qiu 1997). For product R\&D similar results apply although here the higher welfare under Cournot competition is due to higher product quality which directly enhances consumers' surplus (Symeonidis 2003).

In this paper we qualify the celebrated result of Singh and Vives (1984) by showing that Cournot competition can yield lower prices than Bertrand competition in a duopoly with endogenous production costs that supplies demand substitutes. To the best of our knowledge we are the first to establish that lower prices can obtain under Cournot competition with an exogenous market structure. It occurs when products are relatively homogenous, when technological spillovers are strong, and when the $R \& D$ production process is sufficiently efficient. Indeed, under these circumstances the incentives to conduct $R \& D$ are much larger under Cournot competition than under Bertrand competition as in this case much more of the benefits of any cost reduction are given to consumers when competition is over price. As a result, post innovation costs are much lower under Cournot competition which translates into a lower equilibrium price. The range of cases for which total surplus under Cournot competition exceeds that under Bertrand competition is even larger because profits under Bertrand competition are always below those under Cournot competition.

\footnotetext{
1 If firms conduct both process $R \& D$ and product $R \& D$ the incentives comparison between competition types is ambiguous (Lin and Saggi 2002).
} 
A motivating example for our analysis is the semiconductor industry. In this industry firms compete à la Cournot and technological spillovers are strong (De Bondt and Veugelers 1989). It is precisely in this industry that prices have fallen at an astonishing rate of $36 \%$ per year in the 1990s. This pricing pattern can be attributed almost exclusively to quality increases that are associated with product innovations (Aizcorbe 2006). Although the alternative pricing pattern under Bertrand competition is by definition not available, this example does suggest that low prices can also emerge under Cournot competition.

Our analysis is related to that of Qiu (1997). The main difference is that we consider technological spillovers to occur during the R\&D process while Qiu (1997), following d'Aspremont and Jacquemin (1988), assumes that final R\&D results spill over. That is, we consider input spillovers rather than output spillovers. There are three important reasons for doing so (see also Hinloopen 2003). First, empirical studies indicate that spillovers occur during the R\&D process (Kaiser 2002). This finding corresponds to the three channels that Geroski (1995) identifies through which a technological spillover flows: (1) the exchange of ideas through publications, casual encounters and at seminars, (2) the flow of knowledge when a knowledge worker changes employer, and (3) the deduction of the line of reasoning of rivals by observing their behavior.

Second, Qiu (1997) assumes the R\&D results of one firm to be additive (and possibly perfectly additive), to its rival's R\&D results. There are at least three reasons to question this assumption. Note that the two firms operate in the same product market while initially using the same production technology. It is then most likely that there will be some overlap in their independently obtained research results that are aimed at reducing the costs of production. Also, the parts that do not overlap are expected not to be a perfect match to rivals' research results. Finally, differences in corporate culture, research strategies, and internal organization hamper any firm's ability to appropriate fully rival's research results. In sum, high levels of technological output spillovers are not likely to be observed. ${ }^{2}$

Third, Qiu (1997) assumes diminishing returns to scale in R\&D. In combination with additive output spillovers this has a counter-intuitive implication. If one firm has spent more on $R \& D$ than its rival, it could be in the interest of the former to donate its next $R \& D$ investment dollar to its rival and to appropriate the $R \& D$ results through the technological spillover. If these spillovers are substantial this could be a more effective additional cost reduction than spending this last $R \& D$ dollar on own $R \& D$ (Amir 2000).

Recently, Amir et al. (2008) have formalized the latter flaw. They introduce the intuitive criterion that investing in one research laboratory for a firm should be at least as efficient as investing in several independent research laboratories that mutually benefit from spillovers. In particular (Amir et al. 2008): “ The R\&D technology and the spillover process should be such that any total R\&D investment level cannot generate more cost reduction if allocated to $n$ labs, run independently but with spillovers at their natural rate, than if spent all in one lab." This means that any research entity absorbs better its own findings than those acquired through spillovers

\footnotetext{
2 Gersbach and Schmutzler (2003) take an extreme position here by assuming that all of any firm's R\&D results are perfectly additive to any of its rivals' $R \& D$ results.
} 
from other research entities. Indeed, the analysis of Qiu (1997) is at odds with this criterion.

Output spillovers are more beneficial to a firm than input spillovers if there are diminishing returns to scale in $\mathrm{R} \& \mathrm{D}$. At the same time they reduce rivals' production cost more than what input spillovers would do. At forehand, the net effect of switching from output spillovers to input spillovers on the incentives to invest in R\&D is unclear. And because R\&D investments rule the efficiency comparison between Cournot and Bertrand competition in Qiu (1997), it remains to be examined to what extent his analysis hinges on the assumption of output spillovers. For this reason we re-examine the dynamic efficiency of Cournot and Bertrand competition assuming input spillovers. In passing we reveal a technical error in Qiu (1997) related to the stability of equilibria when $R \& D$ is a strategic substitute.

The paper proceeds as follows. In the next section the model is introduced and the technical difference between input and output spillovers is discussed in detail. In Sect. 3 the equilibria are characterized under second-stage Cournot and Bertrand competition. The two competition types are compared next and Sect. 5 concludes.

\section{The model}

We consider a two-stage game. In the first stage firms invest in cost-reducing R\&D. In the second stage they compete either over price or quantity. Market demand in indirect form is given by: ${ }^{3}$

$$
p_{i}=a-\left(q_{i}+\theta q_{j}\right)
$$

$i, j=1,2, i \neq j$, where $p_{i}$ and $q_{i}$ are the respective price and quantity of product $i$, and where $\theta$ captures the extent to which products are differentiated; in case $\theta=1$ products are homogeneous while $\theta=0$ corresponds to completely differentiated products (i.e. both firms have a local monopoly). These polar cases are further ignored, that is, $\theta \in(0,1)$. Unless stated otherwise, $i, j=1,2, i \neq j$ holds throughout the rest of the paper. Market demand in direct form is then given by:

$$
q_{i}=\frac{1}{1-\theta^{2}}\left[(1-\theta) a-\left(p_{i}-\theta p_{j}\right)\right]
$$

The industry consists of two firms each producing one version of the differentiated product. Ex ante marginal costs of production, $c$, are fixed. We assume that both firms are active, that is, $c<a$.

\subsection{Input spillovers versus output spillovers}

Fixed production costs can be reduced by investing in process-innovating R\&D. Note that if one firm conducts $R \& D$, the rival firm can absorb part of this effort without

\footnotetext{
3 This follows from a standard quadratic utility function, see Singh and Vives (1984).
} 
having to pay for it. ${ }^{4}$ This process runs through the technological spillover. In modelling this externality we adhere to the criterion identified by Amir et al. (2008), which states that it should be more beneficial to a firm to invest in one research laboratory than to invest in several independent research laboratories that possibly benefit from mutual spillovers.

Qiu (1997) considers the final results of any firm's R\&D efforts to spill over to its rival. There are diminishing returns to $\mathrm{R} \& \mathrm{D}$ in that any reduction in production costs $x$ comes at a cost $f(x)$, with $f^{\prime}>0, f^{\prime \prime} \geq 0$ and $f(0)=0$. If $\beta \in[0,1]$ represents the technological spillover, firm $i$ realizes a cost reduction of $x_{i}+\beta x_{j}$ if it invests $f\left(x_{i}\right)$ in $\mathrm{R} \& \mathrm{D}$. The criterion of Amir et al. (2008) then requires:

$$
f\left(x_{i}+\beta x_{j}\right) \leq f\left(x_{i}\right)+f\left(x_{j}\right)
$$

For any $f$ with $f(0)=0$ Amir et al. (2008, Proposition 2) show that condition (3) translates into $\beta f^{\prime}(x) \leq f^{\prime}(0)$. This condition is violated for the formulation used by Qiu (1997), being $\bar{f}(z)=\gamma z^{2} / 2$. Put differently, in Qiu (1997) it is beneficial to spread any R\&D investment over a number of different independent research labs rather than investing it in one laboratory. In case of two firms a counter-intuitive result then obtains. Rather than investing its next R\&D euro itself, it could be in the interest of a firm to give this euro to its rival for her to invest in $R \& D$, and to appropriate the result through the output spillover.

In case of input spillovers the reduction in marginal cost brought about by an R\&D investment is determined by an R\&D production function $g$. Diminishing returns to $\mathrm{R} \& \mathrm{D}$ obtain if $g^{\prime}>0, g^{\prime \prime}<0$, and $g(0)=0$. If firm $i$ invests in $\mathrm{R} \& \mathrm{D}$, its effective R\&D investments $X_{i}$ due to the input spillover are given by:

$$
X_{i}=x_{i}+\beta x_{j}
$$

Investing $x_{i}$ thus yields a reduction in cost of $g\left(X_{i}\right)$. The criterion of Amir et al. (2008) then requires:

$$
g\left(X_{i}\right) \leq g\left(x_{i}\right)+g\left(x_{j}\right)
$$

which holds for any $g$ with diminishing returns. Following Amir (2000) we set:

$$
g\left(X_{i}\right)=\sqrt{X_{i} / \gamma}
$$

whereby $\gamma>0$ determines the efficiency of the R\&D phase. A higher value of $\gamma$ corresponds to a less efficient production of $\mathrm{R} \& \mathrm{D}$ results. Note that $\mathrm{R} \& \mathrm{D}$ production function (6) fulfills criterion ( 5).

\footnotetext{
4 It is understood that firms have to conduct at least some R\&D themselves to appropriate rival's R\&D results (for an early recognition of this point see Cohen and Levinthal 1989). We abstain from modelling this absorptive capacity as it would make the analysis intractable (cfr. Kamien and Zang 2000).
} 
Firm $i$ 's profits then equal

$$
\pi_{i}=p_{i} q_{i}-\left(c-y_{i}\right) q_{i}-x_{i},
$$

with $y_{i}=\sqrt{\left(x_{i}+\beta x_{j}\right) / \gamma}$.

\section{Market equilibria}

\subsection{Second-stage Bertrand competition}

Maximizing (7) over price yields equilibrium prices conditional on effective R\&D efforts: ${ }^{5}$

$$
\widehat{p}_{i}\left(X_{i}, X_{j}\right)-c=\frac{(a-c)(2+\theta)(1-\theta)-2 y_{i}-\theta y_{j}}{4-\theta^{2}} .
$$

Inserting (8) into (7) and maximizing the resulting profits over R\&D investments result in the following cost reduction: ${ }^{6,7}$

$$
\widetilde{y}^{B}=\frac{(a-c)\left(2-\theta^{2}-\theta \beta\right)}{\gamma(1+\theta)(2-\theta)\left(4-\theta^{2}\right)-\left(2-\theta^{2}-\theta \beta\right)},
$$

and concomitant total output:

$$
\widetilde{Q}^{B}=\frac{2 \gamma(a-c)\left(4-\theta^{2}\right)}{\gamma(1+\theta)(2-\theta)\left(4-\theta^{2}\right)-\left(2-\theta^{2}-\theta \beta\right)} .
$$

Single-firm equilibrium profits then equal:

$$
\tilde{\pi}^{B}=\frac{\gamma(1+\beta)\left(1-\theta^{2}\right)\left(4-\theta^{2}\right)^{2}-\left(2-\theta^{2}-\theta \beta\right)^{2}}{\gamma(1+\beta)\left(4-\theta^{2}\right)^{2}}\left(\widetilde{q}^{B}\right)^{2},
$$

where $\widetilde{q}^{B}=\widetilde{Q}^{B} / 2$. In equilibrium, consumers' surplus and total surplus respectively are given by:

$$
\widetilde{C S}^{B}=(1+\theta)\left(\widetilde{q}^{B}\right)^{2}
$$

and

$$
\widetilde{T S}^{B}=\frac{\gamma(1+\beta)(1+\theta)\left(4-\theta^{2}\right)^{2}(3-2 \theta)-2\left(2-\theta^{2}-\theta \beta\right)^{2}}{\gamma(1+\beta)\left(4-\theta^{2}\right)^{2}}\left(\widetilde{q}^{B}\right)^{2} .
$$

\footnotetext{
5 A hat refers to a conditional equilibrium outcome.

6 A tilde refers to an unconditional equilibrium expression; superscript $B$ stands for second-stage Bertrand competition.

7 The concomitant second-order and stability conditions are dealt with below.
} 


\subsection{Second-stage Cournot competition}

Maximizing (7) over quantities gives us:

$$
\widehat{q}_{i}\left(X_{i}, X_{j}\right)=\frac{(a-c)(2-\theta)+2 y_{i}-\theta y_{j}}{4-\theta^{2}} .
$$

Maximizing firm profits over R\&D investments after inserting (14) into (7) yields as cost reduction and concomitant total output level: ${ }^{8}$

$$
\widetilde{y}^{C}=\frac{(a-c)(2-\theta \beta)}{\gamma(2+\theta)\left(4-\theta^{2}\right)-(2-\theta \beta)},
$$

and

$$
\widetilde{Q}^{C}=\frac{2 \gamma(a-c)\left(4-\theta^{2}\right)}{\gamma(2+\theta)\left(4-\theta^{2}\right)-(2-\theta \beta)} .
$$

Single-firm profits are given by:

$$
\tilde{\pi}^{C}=\frac{\gamma(1+\beta)\left(4-\theta^{2}\right)^{2}-(2-\theta \beta)^{2}}{\gamma(1+\beta)\left(4-\theta^{2}\right)^{2}}\left(\widetilde{q}^{C}\right)^{2},
$$

with $\widetilde{q}^{C}=\widetilde{Q}^{C} / 2$. Consumers' surplus and total welfare under second-stage Cournot competition then equal:

$$
\widetilde{C S}^{C}=(1+\theta)\left(\widetilde{q}^{C}\right)^{2}
$$

and

$$
\widetilde{T S}^{C}=\frac{\gamma(1+\beta)(3+\theta)\left(4-\theta^{2}\right)^{2}-2(2-\theta \beta)^{2}}{\gamma(1+\beta)\left(4-\theta^{2}\right)^{2}}\left(\widetilde{q}^{C}\right)^{2} .
$$

\subsection{Regularity conditions}

The $R \& D$ stage gives rise to eight regularity conditions. In addition to the two second-order conditions, post-innovation costs have to be positive and the equilibrium has to be stable. The second-order conditions under Bertrand and Cournot competition require, respectively:

$$
\gamma \geq \frac{\left(2-\theta^{2}-\theta \beta\right)^{3}}{\left(1-\theta^{2}\right)\left(4-\theta^{2}\right)^{2}\left(2-\theta^{2}-\theta \beta^{2}\right)},
$$

\footnotetext{
8 Superscript $C$ stands for second-stage Cournot competition.
} 
and

$$
\gamma \geq \frac{(2-\theta \beta)^{3}}{\left(2-\theta \beta^{2}\right)\left(4-\theta^{2}\right)^{2}}
$$

Under Bertrand and Cournot competition positive post-innovation costs respectively imply:

$$
\gamma>\frac{a\left(2-\theta^{2}-\theta \beta\right)}{c(2-\theta)(1+\theta)\left(4-\theta^{2}\right)},
$$

and

$$
\gamma>\frac{a(2-\theta \beta)}{c(2+\theta)\left(4-\theta^{2}\right)}
$$

Finally, the Routh-Hurwitz stability condition is that:

$$
\frac{\partial^{2} \widehat{\pi}_{i}\left(x_{i}, x_{j}\right)}{\partial x_{i}^{2}} \frac{\partial^{2} \widehat{\pi}_{j}\left(x_{i}, x_{j}\right)}{\partial x_{j}^{2}}-\frac{\partial^{2} \widehat{\pi}_{i}\left(x_{i}, x_{j}\right)}{\partial x_{j} \partial x_{i}} \frac{\partial^{2} \widehat{\pi}_{j}\left(x_{i}, x_{j}\right)}{\partial x_{i} \partial x_{j}}>0 .
$$

This condition depends on the strategic nature of the R\&D process. Following Bulow et al. (1985), label decision variable $x$ a strategic substitute in case $\partial^{2} \widehat{\pi}_{i}\left(x_{i}, x_{j}\right) / \partial x_{i} \partial x_{j}<0$, and a strategic complement if $\partial^{2} \widehat{\pi}_{i}\left(x_{i}, x_{j}\right) / \partial x_{i} \partial x_{j}>0$. Accordingly, in a symmetric equilibrium condition (20) boils down to:

$$
\frac{\partial^{2} \pi_{i}\left(x_{i}, x_{j}\right)}{\partial x_{i}^{2}}<\frac{\partial^{2} \pi_{i}\left(x_{i}, x_{j}\right)}{\partial x_{i} \partial x_{j}}
$$

for strategic substitutes. For strategic complements it reads as:

$$
\frac{\partial^{2} \pi_{i}\left(x_{i}, x_{j}\right)}{\partial x_{i}^{2}}<-\frac{\partial^{2} \pi_{i}\left(x_{i}, x_{j}\right)}{\partial x_{i} \partial x_{j}} .
$$

Under Bertrand competition these two stability conditions respectively translate into:

$$
\gamma>\frac{\left(2-\theta^{2}-\theta \beta\right)^{2}}{\left(4-\theta^{2}\right)(2+\theta)(1-\theta)\left(2-\theta^{2}+\theta \beta\right)},
$$

and

$$
\gamma>\frac{\left(2-\theta^{2}-\theta \beta\right)}{\left(4-\theta^{2}\right)(2-\theta)(1+\theta)} .
$$


In case of Cournot competition the two stability conditions are:

$$
\gamma>\frac{(2-\theta \beta)^{2}}{\left(4-\theta^{2}\right)(2-\theta)(2+\theta \beta)},
$$

and

$$
\gamma>\frac{(2-\theta \beta)}{\left(4-\theta^{2}\right)(2+\theta)} .
$$

Five of these regularity conditions are redundant as the following lemma shows.

Lemma 1 The parameter space is bounded by regularity conditions $\mathrm{R} 4, \mathrm{R} 5$ and $\mathrm{R} 7$.

Proof It is immediate that R4 dominates R3, that R5 dominates R6, and that R7 dominates R8. Also, R5 dominates R1 and R7 dominates R2.

Note that Qiu (1997) considers stability conditions only in case R\&D is a strategic complement. In his model the stability conditions for R\&D as a strategic substitute under Cournot and Bertrand competition are respectively given by (using the notation in Qiu 1997):

$$
v>\frac{2(2-\theta \gamma)(1-\theta)}{(2-\gamma)\left(4-\gamma^{2}\right)},
$$

and

$$
v>\frac{2(1-\theta)\left(2-\theta \gamma-\gamma^{2}\right)}{(1-\gamma)(2+\gamma)\left(4-\gamma^{2}\right)},
$$

where $\theta \in[0,1]$ is the output spillover, where $v$ is the measure of the efficiency of the $R \& D$ process, and where $\gamma \in[0,1]$ indicates the extent of product differentiation. The analysis of Qiu (1997) applies only to R\&D that is a strategic complement as it is straightforward to show that conditions (23) and (24) can be more restrictive than the stability conditions when R\&D is a strategic complement.

\section{Cournot versus Bertrand}

\subsection{R\&D investments}

Comparing the effective R\&D efforts of the different competition modes leads to the following proposition:

Proposition 1 For any given $\theta \in(0,1)$ and $\beta \in[0,1], \widetilde{y}^{C}>\widetilde{y}^{B}$ under $\mathrm{R} 4, \mathrm{R} 5$ and R7.

Proof $\widetilde{y}^{C}>\widetilde{y}^{B} \Leftrightarrow(1+\theta)(2-\theta)(2-\theta \beta)>(2+\theta)\left(2-\theta^{2}-\theta \beta\right)$, or $\beta>-1$. 
According to Proposition 1, R\&D activity is higher under Cournot competition than under Bertrand competition. This result replicates Qiu (1997, Proposition 1). ${ }^{9}$ He decomposes the incentives to invest in R\&D into four different effects: a strategic effect, a spillover effect, a size effect and a cost effect. These effects are obtained by totally differentiating the first-order conditions $\partial \pi_{i} / \partial q_{i} \equiv 0$ (under Cournot competition) and $\partial \pi_{i} / \partial p_{i} \equiv 0$ (under Bertrand competition) with respect to $x_{i}$. This yields, respectively (Qiu 1997, p. 225, using his notation):

$$
\frac{\partial \pi_{i}^{C}}{\partial x_{i}}=\overbrace{\frac{1}{\Omega^{C}} \frac{\partial \pi_{i}}{\partial q_{j}} \frac{\partial^{2} \pi_{j}}{\partial q_{i} \partial q_{j}}}^{\text {strategic effect (-) }}+\overbrace{-\frac{\theta}{\Omega^{C}} \frac{\partial \pi_{i}}{\partial q_{j}} \frac{\partial^{2} \pi_{i}}{\partial q_{i}^{2}}}^{\text {spillover effect (-) }}+\overbrace{q_{i}}^{\text {size effect (+) cost effect (-) }}+\overbrace{-v x_{i}}^{\text {s. }} \equiv 0,
$$

where $\Omega^{C}=\left(\partial^{2} \pi_{i} / \partial q_{i}^{2}\right)\left(\partial^{2} \pi_{j} / \partial q_{j}^{2}\right)-\left(\partial^{2} \pi_{i} / \partial q_{j} \partial q_{i}\right)\left(\partial^{2} \pi_{j} / \partial q_{i} q_{j}\right)>0$, and

$$
\frac{\partial \pi^{B}}{\partial x_{i}}=\overbrace{\frac{1}{\Omega^{B}} \frac{\partial q_{i}}{\partial p_{i}} \frac{\partial \pi_{i}}{\partial p_{j}} \frac{\partial^{2} \pi_{j}}{\partial p_{i} \partial p_{j}}}^{\text {strategic effect (-) }}+\overbrace{-\frac{\theta}{\Omega^{B}} \frac{\partial q_{j}}{\partial p_{j}} \frac{\partial \pi_{i}}{\partial p_{j}} \frac{\partial^{2} \pi_{i}}{\partial p_{i}^{2}}}^{\text {spillover effect (-) }}+\overbrace{q_{i}}^{\text {size effect (+) cost effect (-) }}+\overbrace{-v x_{i}}^{\text {co }} \equiv 0,
$$

where $\Omega^{B}=\left(\partial^{2} \pi_{i} / \partial p_{i}^{2}\right)\left(\partial^{2} \pi_{j} / \partial p_{j}^{2}\right)-\left(\partial^{2} \pi_{i} / \partial p_{j} \partial p_{i}\right)\left(\partial^{2} \pi_{j} / \partial p_{i} p_{j}\right)>0$. The spillover, size and cost effect have an identical sign under Cournot and Bertrand competition. The spillover effect and the cost effect are negative. The more expensive is R\&D, the lower will be the R\&D investment. And the free flow of knowledge to competitors obviously reduces the incentive to invest in $R \& D$. The size effect is positive and refers to the quantities produced. The more a firm produces, the more profitable will be a reduction in production costs, the higher is the incentive to invest in $R \& D$ that creates such a cost reduction.

The strategic effect however carries an opposite sign. With Cournot competition it is positive as quantities are strategic substitutes. It thus pays to have lower marginal cost as that translates into a larger market share and higher profits. With Bertrand competition it is negative as prices are strategic complements. Reduced marginal costs induce a firm to cut price. Rivals' reaction will be to lower its price as well. In the end this reduces both firms' profits.

The switch from output spillovers to input spillovers yields under Cournot and Bertrand competition respectively the following two decompositions:

$$
\frac{\partial \pi_{i}^{C}}{\partial x_{i}}=\overbrace{\frac{1}{\Omega^{C}} \frac{\partial \pi_{i}}{\partial q_{j}} \frac{\partial^{2} \pi_{j}}{\partial q_{i} \partial q_{j}}}^{\text {strategic effect (-) }}+\overbrace{-\frac{\beta y_{i}}{y_{j} \Omega^{C}} \frac{\partial \pi_{i}}{\partial q_{j}} \frac{\partial^{2} \pi_{i}}{\partial q_{i}^{2}}}^{\text {spillover effect (-) }}+\overbrace{q_{i}}^{\text {size effect }}+\overbrace{-2 \gamma y_{i}}^{\text {cost effect (-) }} \equiv 0,
$$

\footnotetext{
9 The ranking in Proposition 1 is also found by Breton et al. (2004) who replicate the analysis of Qiu (1997) within an infinite horizon setting.
} 
and

$$
\frac{\partial \pi^{B}}{\partial x_{i}}=\overbrace{\frac{1}{\Omega^{B}} \frac{\partial q_{i}}{\partial p_{i}} \frac{\partial \pi_{i}}{\partial p_{j}} \frac{\partial^{2} \pi_{j}}{\partial p_{i} \partial p_{j}}}^{\text {strategic effect (-) }}+\overbrace{-\frac{\beta y_{i}}{y_{j} \Omega^{B}} \frac{\partial q_{j}}{\partial p_{j}} \frac{\partial \pi_{i}}{\partial p_{j}} \frac{\partial^{2} \pi_{i}}{\partial p_{i}^{2}}}^{\text {spillover effect (-) }}+\overbrace{q_{i}}^{\text {size effect (+) }}+\overbrace{-2 \gamma y_{i}}^{\text {cost effect }}(-) \text {.) }
$$

Comparing (25) with (27) and (26) with (28) shows that in a symmetric equilibrium the difference between the two models as to the R\&D investment incentives is ruled by the difference in the cost effect. As this effect is of larger magnitude with input spillovers, in equilibrium the R\&D investments with output spillovers will exceed those with input spillovers. ${ }^{10}$ That is, with input spillovers the R\&D intensity is lower than with output spillovers under both Cournot and Bertrand competition. As Amir (2000, p. 1029) notes: “At a quantitative level, the d'Aspremont-Jacquemin model has a systematic bias towards higher levels of R\&D than the Kamien-Muller-Zang model".

The actual difference in R\&D activity that leads to the ranking in Proposition 1 is closely related to the efficiency of the $\mathrm{R} \& \mathrm{D}$ process. That is:

Lemma 2 Under R4, R5 and R7, the difference in R\&D activity under Cournot and Bertrand competition is larger the more efficient is the $R \& D$ process.

Proof Note that

$$
\begin{aligned}
\tilde{y}^{C}-\widetilde{y}^{B} & \\
& =\frac{\gamma \theta^{3}\left(4-\theta^{2}\right)(1+\beta)(a-c)}{\left[\gamma(2+\theta)\left(4-\theta^{2}\right)-(2-\theta \beta)\right]\left[\gamma(1+\theta)(2-\theta)\left(4-\theta^{2}\right)-\left(2-\theta^{2}-\theta \beta\right)\right]} .
\end{aligned}
$$

Then observe that:

$$
\frac{\partial\left(\widetilde{y}^{C}-\widetilde{y}^{B}\right)}{\partial \gamma}<0 \Leftrightarrow \gamma^{2}>\frac{(2-\theta \beta)\left(2-\theta^{2}-\theta \beta\right)}{(1+\theta)\left(4-\theta^{2}\right)^{3}} .
$$

This last condition is less restrictive than condition R7 if, and only if $(2-\theta \beta)^{3}(1+$ $\theta)\left(4-\theta^{2}\right)-\left(2-\theta^{2}-\theta \beta\right)(2-\theta)^{2}(2+\theta \beta)^{2}>0$. Considering the left-hand side (LHS) of this last inequality, the result then follows as $\min _{\{\theta, \beta\}} L H S=\left.\lim _{\theta \rightarrow 0} L H S\right|_{\beta=1}=0$.

The larger is the reduction in production costs for any level of R\&D investment, the more prominent is the strategic effect that affects any firms' incentive to conduct $R \& D$. Hence, the more efficient is the R\&D process, the larger is the difference in R\&D investments under Cournot competition vis-à-vis Bertrand competition.

10 It is left to the reader to check this specifically through comparison of the equilibrium expressions for R\&D investments with input and output spillovers. 


\subsection{Profits}

Under Cournot competition firms invest more in R\&D than under Bertrand competition (Proposition 1). And larger R\&D investments reduce profits, all else equal. The following proposition shows however that these higher R\&D costs under Cournot competition are more than offset by the concomitant reduction in production cost:

Proposition 2 For any given $\theta \in(0,1)$ and $\beta \in[0,1], \tilde{\pi}^{C}>\tilde{\pi}^{B}$ under R4, R5 and R7.

Proof First note that $\tilde{\pi}^{C}-\tilde{\pi}^{B}=\gamma(a-c)^{2}(A-B) /(1+\beta)$, where

$$
A=\frac{\gamma(1+\beta)\left(4-\theta^{2}\right)^{2}-(2-\theta \beta)^{2}}{\left[\gamma(2+\theta)\left(4-\theta^{2}\right)-(2-\theta \beta)\right]^{2}}
$$

and

$$
B=\frac{\gamma(1+\beta)\left(1-\theta^{2}\right)\left(4-\theta^{2}\right)^{2}-\left(2-\theta^{2}-\theta \beta\right)^{2}}{\left[\gamma(1+\theta)(2-\theta)\left(4-\theta^{2}\right)-\left(2-\theta^{2}-\theta \beta\right)\right]^{2}} .
$$

Then observe that:

$$
\tilde{\pi}^{C}-\tilde{\pi}^{B}>0 \Leftrightarrow \gamma>\frac{2\left(4-3 \theta^{2}\right)-\theta(1-\beta)\left(\theta^{2}-2 \theta-4\right)}{2(1+\theta)\left(4-\theta^{2}\right)^{2}} .
$$

This last condition is less restrictive than condition $\mathrm{R} 7$ if, and only if, $(1-\beta)$ $\left[32+16 \theta-12 \theta^{2}-16 \theta \beta-2 \theta^{3}(1+\beta)+8 \theta^{3} \beta\right]+\theta^{2} \beta\left[8 \beta-\theta^{2}(1+\beta)\right]>0$. Considering the LHS of this last inequality the result then follows as $\min _{\{\theta, \beta\}} L H S=$ $\left.\lim _{\theta \rightarrow 0} L H S\right|_{\beta=1}=0$.

Proposition 2 states that producers' surplus under Cournot competition is always larger than under Bertrand competition. Because post-innovation production costs are lower under Cournot competition, this larger producers' surplus can exceed the lower consumers' surplus in Cournot markets compared to Bertrand markets. But before we analyze total surplus we first consider consumers' surplus.

\subsection{Price}

For comparing prices under Cournot and Bertrand competition we introduce the following assumption:

$$
\gamma<\frac{1}{4-\theta^{2}}
$$

If assumption A1 holds the R\&D process is labelled 'efficient'. According to Lemma 2 this corresponds to situations where post-innovation cost under Cournot 


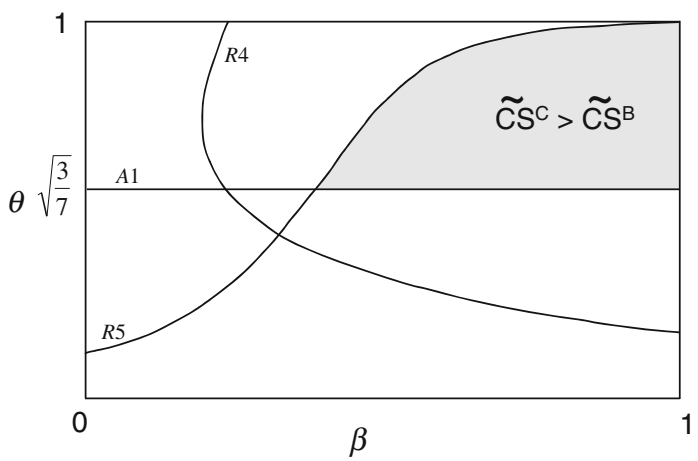

Fig. 1 Comparing consumers' surplus with Cournot and Bertrand competition under assumption A1 and regularity conditions $\mathrm{R} 4$ and $\mathrm{R} 5\left(a=100, c=70, \gamma=\frac{7}{25}\right)$

competition are particularly low compared to post-innovation costs under Bertrand competition. As will be shown below, this allows the equilibrium price under Cournot competition to be lower than under Bertrand competition. First note that assumption A1 does not rule out the existence of equilibria:

Lemma 3 The set where regularity conditions $\mathrm{R} 4, \mathrm{R} 5, \mathrm{R} 7$ and assumption A1 hold is not empty.

Proof For A1 and R4 to hold jointly it must be that $1<a / c<(2+\theta) /(2-\theta \beta)$, or $2(a-c)<\theta(a \beta+c)$. Indeed, $a$ and $c$ can always be chosen such that this inequality holds. For A1 and R5 to hold jointly it must be that $1>\left(2-\theta^{2}-\theta \beta\right)^{2} /(2+\theta)(1-\theta)(2-$ $\left.\theta^{2}+\theta \beta\right)$, or $\beta>\left(6-3 \theta^{2}-\theta-\sqrt{(1-\theta)\left(36+16 \theta-19 \theta^{2}-9 \theta^{3}\right)}\right) / 2 \theta=f(\theta)$. Note that $f(\theta)$ is continuous and strictly increasing in $\theta \in(0,1)$, that $\lim _{\theta \rightarrow 0} f(\theta)=$ $\frac{1}{3}$, and that $\lim _{\theta \rightarrow 1} f(\theta)=1$. For A1 and R7 to hold jointly it must be that $1>$ $(2-\theta \beta)^{2} /(2-\theta)(2+\theta \beta)$, or $\beta>(6-\theta-\sqrt{(18-\theta)(2-\theta)}) / 2 \theta=g(\theta)$. Note that $g(\theta)$ is continuous and strictly increasing in $\theta \in(0,1)$, that $\lim _{\theta \rightarrow 0} g(\theta)=\frac{1}{3}$, and that $\lim _{\theta \rightarrow 1} g(\theta)=(5-\sqrt{17}) / 2 \approx 0.438$.

Figure 1 displays the admissible parameter space and assumption A1 for particular values of $a, c$, and $\gamma$. From the proof of Lemma 3 follows that $f(\theta)-g(\theta)>0$ $\forall \theta \in(0,1)$. Hence, under assumption A1 the admissible parameter space is confined by conditions R4 and R5.

We can now state the main result of our analysis.

Proposition 3 For any given $\theta \in(0,1)$ and $\beta \in[0,1], \widetilde{p}^{C}<\widetilde{p}^{B}$ under R4, R5, R7, and $\mathrm{A} 1$.

Proof Lower prices obtain under Cournot competition than under Bertrand competition if, and only if, $\widetilde{Q}^{C}>\widetilde{Q}^{B}$, or $\gamma<1 /\left(4-\theta^{2}\right)$.

Proposition 3 conveys our new message. In a duopoly with substitutable products, prices can be lower under Cournot competition than under Bertrand competition. This 
happens when post-innovation costs under Cournot competition are sufficiently below post-innovation costs under Bertrand competition. Considering the admissible parameter space in Lemma 3, this occurs when the R\&D process is efficient, when spillovers are substantial, and when products are not too differentiated. It is precisely under these circumstances that the benefits of any cost reduction are transferred much more to consumers under Bertrand competition than under Cournot competition. Hence, production costs under Cournot competition are much lower than under Bertrand competition which allows the equilibrium price to be lower as well. ${ }^{11}$

\subsection{Welfare}

As producers' surplus is always higher under Cournot competition than under Bertrand competition (Proposition 2), the result in Proposition 3 carries over to total surplus:

Proposition 4 For any given $\theta \in(0,1)$ and $\beta \in[0,1], \widetilde{T S}^{C}>\widetilde{T S}^{B}$ under R4, R5, $\mathrm{R} 7$, and $\mathrm{A} 1$.

For a less efficient R\&D production process it is still possible that total surplus under Cournot competition exceeds total surplus under Bertrand competition. In that case consumers' surplus is lower when firms compete over quantities (Proposition 3). But this lower consumers' surplus is then more than compensated for by the higher producers' surplus under Cournot competition. To establish this result it is convenient to distinguish two cases: (1) no input spillovers, and (2) positive input spillovers.

Proposition 5 For any given $\theta \in(0,1)$ and $\beta=0, \widetilde{T S}^{C}<\widetilde{T S}^{B}$ under R4, R5, R7, and $\neg \mathrm{A} 1$.

Proof See Appendix.

Absent input spillovers the traditional welfare comparison emerges provided that the $R \& D$ production process is not too efficient. For positive input spillovers the difference in R\&D investment incentives under Cournot and Bertrand competition becomes more pronounced. Indeed, a threshold value of the input spillover exists beyond which total surplus is larger if firms compete over quantity rather than over price:

Proposition 6 Suppose that $\beta \in(0,1]$, and that $\mathrm{R} 4, \mathrm{R} 5, \mathrm{R} 7$ and $\neg \mathrm{A} 1$ hold. Then, given $\theta \in(0,1), \exists \bar{\gamma}(\theta)$ such that

(i) if $\gamma>\bar{\gamma}(\theta)$, then $\widetilde{T S}^{B}-\widetilde{T S}^{C}>0 \forall \beta \in(0,1]$; and

11 The result in Proposition 3 does not hinge on spillovers to be input spillovers. In Qiu (1997) the parameter space is bounded by five conditions (realizing that R\&D can also be a strategic substitute and using the notation in Qiu 1997; see Sect. 3.3): $v>2(2-\theta \gamma)^{2} /\left(4-\gamma^{2}\right)^{2}, v>2(2-\theta \gamma)(1+\theta) /(2+\gamma)\left(4-\gamma^{2}\right)$, $v>2 a(1+\theta)(2-\theta \gamma) / c(2+\gamma)\left(4-\gamma^{2}\right), v>2\left(2-\theta \gamma-\gamma^{2}\right)^{2} /\left(1-\gamma^{2}\right)\left(4-\gamma^{2}\right)^{2}$, and $v>$ $2(1-\theta)\left(2-\theta \gamma-\gamma^{2}\right) /(1-\gamma)(2+\gamma)\left(4-\gamma^{2}\right)$. The condition corresponding to assumption A1 is that $v<2(1+\theta) /\left(4-\gamma^{2}\right)$. For instance, the combination of parameter values $a=100, c=70, \theta=0.95$ and $\gamma=0.95$ lies within the admissible parameter space and it fulfills the additional assumption. The equilibrium price under Cournot competition is then 65.4 while under Bertrand competition it is 67.9. 
(ii) if $\gamma<\bar{\gamma}(\theta)$, then $\exists \bar{\beta}(\theta) \in(0,1]$ such that

$$
\widetilde{T S}^{B}-\widetilde{T S}^{C} \begin{cases}>0 & \forall \beta<\bar{\beta}(\theta) \\ =0 & \text { if } \beta=\bar{\beta}(\theta) \\ <0 & \forall \beta>\bar{\beta}(\theta) .\end{cases}
$$

Proof See Appendix.

Technological spillovers carry a positive externality that raises total surplus. The combination of large R\&D investments and strong technological spillovers contributes in particular to total surplus. Hence, as under Cournot competition R\&D investments exceed those under Bertrand competition, total surplus can be larger under quantity competition when the input spillover is strong enough.

\section{Conclusions}

We have shown that in a duopoly with substitutable goods where firms invest in process $\mathrm{R} \& \mathrm{D}$, price can be lower under Cournot competition than under Bertrand competition. This occurs when the R\&D process is efficient, when spillovers are substantial, and when products are not too differentiated. Under these circumstances much more of the benefit of any cost reduction are given to consumers under Bertrand competition than under Cournot competition. As a result the post-innovation costs are much lower under Cournot competition than under Bertrand competition leading to lower prices when firms compete over quantities.

The robustness of our result should be checked along several dimensions. An obvious scenario would be to consider cooperative R\&D prior to the production stage. Allowing firms to cooperate in R\&D is an important policy tool to enhance incentives towards investment in R\&D. As this policy is driven foremost by the resulting internalization of the technological spillover, it needs to be examined whether it affects the conclusion that price can be lower under Cournot competition than under Bertrand competition.

Acknowledgments Thanks are due to two anonymous referees, to Thomas Rønde and to seminar participants at the Katholieke Universiteit Leuven, at the University of Amsterdam, at the joint KULeuven/ZEW Workshop on the Economics of Innovation (Mannheim, December 2007), and at the annual conference of the Scottish Economic Society (Perth, April 2008), and European Association for Research in Industrial Economics (Toulouse, September 2008).

Open Access This article is distributed under the terms of the Creative Commons Attribution Noncommercial License which permits any noncommercial use, distribution, and reproduction in any medium, provided the original author(s) and source are credited.

\section{Appendix A}

\section{A.1 Proof of Proposition 5}

First note that:

$$
\widetilde{T S}^{B}-\widetilde{T S}^{C}=\frac{\gamma(a-c)^{2}}{\Delta_{B}^{2} \Delta_{C}^{2}} F(\gamma ; \theta),
$$




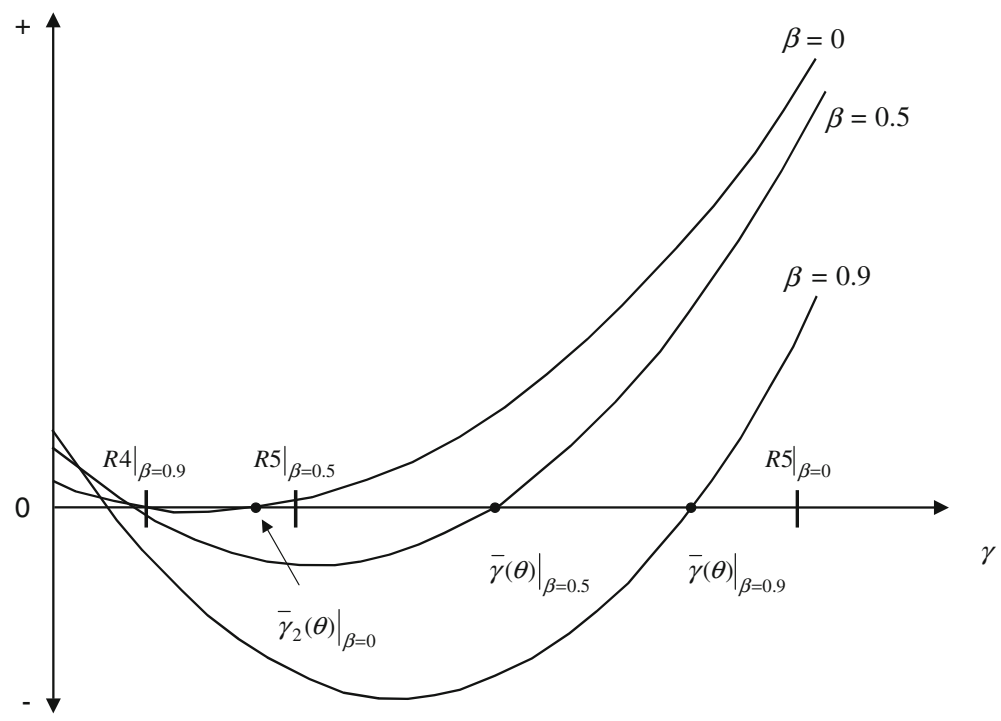

Fig. $2 G(\gamma ; \beta, \theta)$ for different levels of R\&D input spillovers; $a=100, c=70, \theta=0.9$

where $\Delta_{B}=\gamma(1+\theta)(2-\theta)\left(4-\theta^{2}\right)-\left(2-\theta^{2}\right), \Delta_{C}=\gamma(2+\theta)$ $\left(4-\theta^{2}\right)-2$, and $F(\gamma, \theta)=\left[\gamma\left(4-\theta^{2}\right)^{2}(1+\theta)(3-2 \theta)-2\left(2-\theta^{2}\right)^{2}\right] \Delta_{C}^{2}-$ $\left[\gamma\left(4-\theta^{2}\right)^{2}(3+\theta)-8\right] \Delta_{B}^{2}$. Define $G(\gamma ; \theta)=F(\gamma ; \theta) /\left(\gamma \theta^{2}\left(4-\theta^{2}\right)\right)$. Obviously, $\operatorname{sign}\left(\widetilde{T S}^{B}-\widetilde{T S}{ }^{C}\right)=\operatorname{sign}(G(\gamma ; \theta))$. Note that $G(\gamma ; \theta)=\gamma^{2} g_{1}+\gamma g_{2}+g_{3}$, where $g_{1}=\left(4-\theta^{2}\right)^{3}(1+\theta)\left(4-2 \theta-\theta^{2}\right), g_{2}=-2\left(4-\theta^{2}\right)^{2}(1+\theta)\left(4-\theta-\theta^{2}\right)+2 \theta(4-$ $\left.\theta^{2}\right)\left(8+4 \theta-4 \theta^{2}-\theta^{3}\right)$, and $g_{3}=\left(4-\theta^{2}\right)\left(4+4 \theta-3 \theta^{2}-\theta^{3}\right)-8 \theta\left(2-\theta^{2}\right)$. It follows that $G(\gamma ; \theta)$ is strictly convex in $\gamma$ as $\partial^{2} G(\gamma ; \theta) / \partial \gamma^{2}=2 g_{1}>0$ (indeed: $\left.\min _{\{\theta\}} g_{1}=\lim _{\theta \rightarrow 1} g_{1}=54\right)$. Moreover, $g_{2}^{2}-4 g_{1} g_{3}>0 \forall \theta \in(0,1)$. Hence, given any $\theta \in(0,1)$, there are two real solutions to $G(\gamma ; \theta)=0$, in particular:

$$
\bar{\gamma}_{1}(\theta)=\frac{-g_{2}-\sqrt{g_{2}^{2}-4 g_{1} g_{3}}}{2 g_{1}}, \quad \text { and } \quad \bar{\gamma}_{2}(\theta)=\frac{-g_{2}+\sqrt{g_{2}^{2}-4 g_{1} g_{3}}}{2 g_{1}} \text {. }
$$

When $\beta=0$, regularity condition R5 is most binding. Label the resulting threshold value on the efficiency parameter $\gamma^{*}$. The result then follows as $\min _{\theta}\left\{\gamma^{*}-\bar{\gamma}_{2}(\theta)\right\}=$ $\lim _{\theta \rightarrow 0}\left\{\gamma^{*}-\bar{\gamma}_{2}(\theta)\right\}=0$ (see also Fig. 2).

\section{A.2 Proof of Proposition 6}

This proofs is a general version of that in Section "Proof of Proposition 5". Observe that:

$$
\widetilde{T S}^{B}-\widetilde{T S}{ }^{C}=\frac{\gamma(a-c)^{2}}{(1+\beta) \Delta_{B}^{2} \Delta_{C}^{2}} F(\gamma ; \beta, \theta),
$$


where $\Delta_{B}=\gamma(1+\theta)(2-\theta)\left(4-\theta^{2}\right)-\left(2-\theta^{2}-\theta \beta\right), \Delta_{C}=\gamma(2+\theta)\left(4-\theta^{2}\right)-(2-\theta \beta)$, and $F(\gamma, \beta, \theta)=\left[\gamma(1+\beta)\left(4-\theta^{2}\right)^{2}(1+\theta)(3-2 \theta)-2\left(2-\theta^{2}-\theta \beta\right)^{2}\right] \Delta_{C}^{2}-$ $\left[\gamma(1+\beta)\left(4-\theta^{2}\right)^{2}(3+\theta)-2(2-\theta \beta)^{2}\right] \Delta_{B}^{2}$. Again we consider the related function $G(\gamma ; \beta, \theta)=F(\gamma ; \beta, \theta) /\left(\gamma \theta^{2}\left(4-\theta^{2}\right)\right)$. It follows that $\operatorname{sign}\left(\widetilde{T S}^{B}-\widetilde{T S}^{C}\right)=$ $\operatorname{sign}(G(\gamma ; \beta, \theta))$. Note that $G(\gamma ; \beta, \theta)=\gamma^{2} g_{1}+\gamma g_{2}+g_{3}$, where $g_{1}=(1+\beta)$ $\left(4-\theta^{2}\right)^{3}(1+\theta)\left(4-2 \theta-\theta^{2}\right), g_{2}=-2(1+\beta)\left(4-\theta^{2}\right)^{2}(1+\theta)\left(4-\theta^{2}-\theta(1-\beta)\right)-$ $2\left(4-\theta^{2}\right)\left[\left(4+2 \theta-\theta^{2}\right)(2-\theta \beta)^{2}-(2+\theta)^{2}\left(4-2 \theta \beta-\theta^{2}\right)\right]$, and $g_{3}=(1+\beta)$ $\left(4-\theta^{2}\right)\left[2(2-\theta \beta)(1+\theta+\theta \beta)-(3+\theta) \theta^{2}\right]-4 \theta(1+\beta)(2-\theta \beta)\left(2-\theta^{2}-\theta \beta\right)$. Then note that $G(\gamma ; \beta, \theta)$ is strictly convex in $\gamma$ as $\partial^{2} G(\gamma ; \beta, \theta) / \partial \gamma^{2}=2 g_{1}>0$ (indeed: $\left.\min _{\{\theta, \beta\}} g_{1}=\lim _{\theta \rightarrow 1, \beta \rightarrow 0} g_{1}=54\right)$. Moreover, $g_{2}^{2}-4 g_{1} g_{3}>0 \forall \theta \in(0,1)$. Hence, given any $\theta \in(0,1)$, there are two real solutions to $G(\gamma ; \beta, \theta)=0$, in particular:

$$
\bar{\gamma}_{1}(\theta)=\frac{-g_{2}-\sqrt{g_{2}^{2}-4 g_{1} g_{3}}}{2 g_{1}}, \text { and } \bar{\gamma}_{2}(\theta)=\frac{-g_{2}+\sqrt{g_{2}^{2}-4 g_{1} g_{3}}}{2 g_{1}} \text {. }
$$

Only the larger root needs to be considered as $\min _{\theta, \beta}\left\{\gamma^{*}-\bar{\gamma}_{1}(\theta)\right\}=\lim _{\theta \rightarrow 0}\left\{\gamma^{*}-\right.$ $\left.\bar{\gamma}_{2}(\theta)\right\}\left.\right|_{\beta=1}=0$, where $\gamma^{*}$ is the threshold value induced by R7. Label the larger $\operatorname{root} \bar{\gamma}(\theta)$. Then observe that $\min _{\theta, \beta}\{\partial \bar{\gamma}(\theta) / \partial \beta\}=\lim _{\theta \rightarrow 0} \partial \bar{\gamma}(\theta) /\left.\partial \beta\right|_{\beta=0.5}=0$. This gives rise to the different lines as drawn in Fig. 2 for different values of $\beta$. Obviously, for any $\gamma>\bar{\gamma}(\theta)$ we are in situation (1) while situation (2) emerges for any $\gamma>\bar{\gamma}(\theta)$. The rest of the proof then follows.

\section{References}

Aizcorbe AM (2006) Why are semiconductor price indexes fall so fast in the 1990s? A decomposition. Econ Inq 44:485-496

Amir R (2000) Modelling imperfectly appropriable R\&D via spillovers. Int J Ind Organ 18:1013-1032

Amir R, Jim JY, Troege M (2008) On additive spillovers and returns to scale in R\&D. Int J Ind Organ 26:695-703

Breton M, Turki A, Zaccour G (2004) Dynamic model of R\&D spillovers, and efficiency of Bertrand and Cournot equilibria. J Optim Theory Appl 123:1-25

Bulow J, Geanakoplos J, Klemperer P (1985) Multimarket oligopoly: strategic substitutes and complements. J Political Econ 93:488-511

Cellini R, Lambertini L, Ottaviano GIP (2004) Welfare in a differentiated oligopoly with free entry: a cautionary note. Res Econ 58:125-133

Cheng (1985) Comparing Bertrand and Cournot equilibria: a geometric approach. RAND J Econ 16:146152

Cohen WM, Levinthal DA (1989) Innovation and learning: the two faces of R\&D. Econ J 99:569-596

d'Aspremont C, Jacquemin A (1988) Cooperative and noncooperative R\&D in duopoly with spillovers. Am Econ Rev 78:1133-1137

De Bondt R, Veugelers R (1989) Informatie en kennis in de economie. In: de Bondt R, Veugelers R (eds) Referatenboek (23ste VWEC). Leuven Universitaire Pers, Leuven, pp 19-33

Geroski PA (1995) Do spillovers undermine the incentive to innovate? In: Dowrick S (ed) Economic approaches to innovation. Edward Elgar, Alderschot, pp 76-97

Gersbach H, Schmutzler A (2003) Endogenous spillovers and incentives to innovate. Econ Theory 21:59-79

Häckner J (2000) A note on price and quantity competition in differentiated oligopolies. J Econ Theory 93:233-239

Hinloopen J (2003) R\&D efficiency gains due to cooperation. J Econ 80:107-125 
Kaiser U (2002) Measuring knowledge spillovers in manufacturing and services: an empirical assessment of alternative approaches. Res Policy 31:125-144

Kamien M, Zang I (2000) Meet me halfway: research joint ventures and absorptive capacity. Int J Ind Organ 18:995-1013

Lin P, Saggi K (2002) Product differentiation, process R\&D and the nature of market competition. Eur Econ Rev 46:201-211

Martin S (2002) Advanced industrial economics. Blackwell, Oxford

Mukherjee A (2005) Price and quantity competition under free entry. Res Econ 59:335-344

Qiu LD (1997) On the dynamic efficiency of Bertrand and Cournot equilibria. J Econ Theory 75:213-229

Singh N, Vives X (1984) Price and quantity competition in a differentiated duopoly. RAND J Econ 15:546554

Symeonidis G (2003) Comparing Cournot and Bertrand equilibria in a differentiated duopoly with product R\&D. Int J Ind Organ 21:39-56

Vives X (1985) On the efficiency of Bertrand and Cournot equilibria with product differentiation. J Econ Theory 36:166-175

Zanchettin P (2006) Differentiated duopoly with asymmetric costs. J Econ Manag Strategy 15:999-1015 